\title{
Neurofibromin Is the Major Ras Inactivator in Dendritic Spines
}

\author{
Ana F. Oliveira ${ }^{1,4}$ and Ryohei Yasuda ${ }^{1,2,3}$ \\ ${ }^{1}$ Department of Neurobiology, Duke University Medical Center, Durham, North Carolina 27710, ${ }^{2}$ Howard Hughes Medical Institute, Duke University \\ Medical Center, Durham, North Carolina 27710, ${ }^{3}$ Max-Planck Florida Institute for Neuroscience, Jupiter, Florida 33458, and ${ }^{4}$ Doctoral Program in \\ Biomedicine and Experimental Biology, Center for Neuroscience and Cell Biology, University of Coimbra, 3004-517 Coimbra, Portugal
}

In dendritic spines, Ras plays a critical role in synaptic plasticity but its regulation mechanism is not fully understood. Here, using a fluorescence resonance energy transfer/fluorescence lifetime imaging microscopy-based Ras imaging technique in combination with 2-photon glutamate uncaging, we show that neurofibromin, in which loss-of-function mutations cause Neurofibromatosis Type 1 (NF1), contributes to the majority $(\sim 90 \%)$ of Ras inactivation in dendritic spines of pyramidal neurons in the CA1 region of the rat hippocampus. Loss of neurofibromin causes sustained Ras activation in spines, which leads to impairment of spine structural plasticity and loss of spines in an activity-dependent manner. Therefore, deregulation of postsynaptic Ras signaling may explain, at least in part, learning disabilities associated with NF1.

Key words: NF1; hippocampus; LTP; NMDA receptor; rats; small GTPase; synaptic plasticity

\section{Introduction}

Neurofibromatosis Type 1 (NF1) is caused by loss-of-function mutations of the $\mathrm{Nf1}$ gene and is associated with learning disabilities. $N f 1$ encodes neurofibromin, a protein with multiple functions including Ras inactivation (Ras GTPase-activating protein or RasGAP; Ballester et al., 1990; Martin et al., 1990; Xu et al., 1990) and adenylyl cyclase (AC) activation (Guo et al., 1997; Guo et al., 2000), as well as interaction with a number of molecules such as NMDA receptors (NMDARs), syndecan-2, and valosincontaining protein (VCP; Husi et al., 2000; Hsueh et al., 2001; Wang et al., 2011). Heterozygous knock-out mice of Nf1, which serve as an NF1 model (Silva et al., 1997), show impaired LTP and learning, which can be rescued by inhibition of the Ras pathway (Costa et al., 2002; Li et al., 2005; Guilding et al., 2007). Drosophila carrying $N f 1$-null mutations also exhibit learning defects, which are found to be correlated with reduced AC activity (Guo et al., 1997; Guo et al., 2000). Therefore, regulation of both Ras and AC signaling by neurofibromin appears to be important for learning and memory.

Neurofibromin is expressed in dendritic spines of pyramidal neurons (Hsueh et al., 2001) and regulates spine density (Lin et al., 2007; Wang et al., 2011). It has been reported that regulation

\footnotetext{
Received July 22, 2013; revised 0ct. 28, 2013; accepted Nov. 18, 2013.

Author contributions: A.F.O. and R.Y. designed research; A.F.O. performed research; A.F.O. and R.Y. analyzed data; A.F.O. and R.Y. wrote the paper.

This study was supported by National Institutes of Health and the Howard Hughes Medical Institute. A.F.O. is supported by a doctoral studentship by the Portuguese Science Foundation and by a Young Investigator Award from the Children's Tumor Foundation. We thank L. Colgan and J. Christy for critical reading, A. Wan for making slices, D. Kloetzer for laboratory management, and other members of the Yasuda laboratory for helpful discussions.

The authors declare no competing financial interests.

Correspondence should be addressed to Ryohei Yasuda, 1 Max Planck Way, Max-Planck Florida Institute for Neuroscience, Jupiter, FL 33458. E-mail: Ryohei.Yasuda@mpfi.org.

DOI:10.1523/JNEUROSCI.3096-13.2014

Copyright $\odot 2014$ the authors $\quad 0270-6474 / 14 / 340776-08 \$ 15.00 / 0$
}

of AC by neurofibromin (Lin et al., 2007) and interaction of neurofibromin with VCP (Wang et al., 2011) and syndecan-2 (Lin et al., 2007) is required for the normal development of spines. The roles of Ras inactivation by neurofibromin in learning and LTP have been also studied extensively. In particular, Ras regulation by neurofibromin in interneurons was found to play a significant role in LTP and hippocampal-dependent learning (Costa et al., 2002; Cui et al., 2008). However, it remains elusive how the RasGAP function of neurofibromin may shape the spatiotemporal pattern of Ras activation in dendritic spines and how it may affect the regulation of the structure and function of dendritic spines. Ras signaling in dendritic spines of pyramidal neurons is required for many forms of synaptic plasticity, including LTP, spine structural plasticity, and new spine formation (Manabe et al., 2000; Wu et al., 2001; Zhu et al., 2002; Thomas and Huganir, 2004; Harvey et al., 2008; Ye and Carew, 2010; Stornetta and Zhu, 2011). It has been proposed that both hypo- and hyperactivation of Ras in spines leads to impairment in synaptic plasticity (Stornetta and Zhu, 2011). Therefore, Ras inactivation by neurofibromin in dendritic spines may play an important role in regulating the plasticity of dendritic spines.

Here, we investigated the role of neurofibromin in Ras signaling and morphological plasticity of dendritic spines in CA1 pyramidal neurons. Using a combination of two-photon fluorescence lifetime imaging (2pFLIM) and two-photon glutamate uncaging, we found that neurofibromin contributes to the majority of Ras inactivation in dendritic spines and that Ras inactivation by neurofibromin is required for sustained spine enlargement associated with LTP and maintenance of spine density.

\section{Materials and Methods}

Statistics. Significance was tested by ANOVA, followed by the least significant difference post hoc tests. Significance level was set to 0.05 . All 

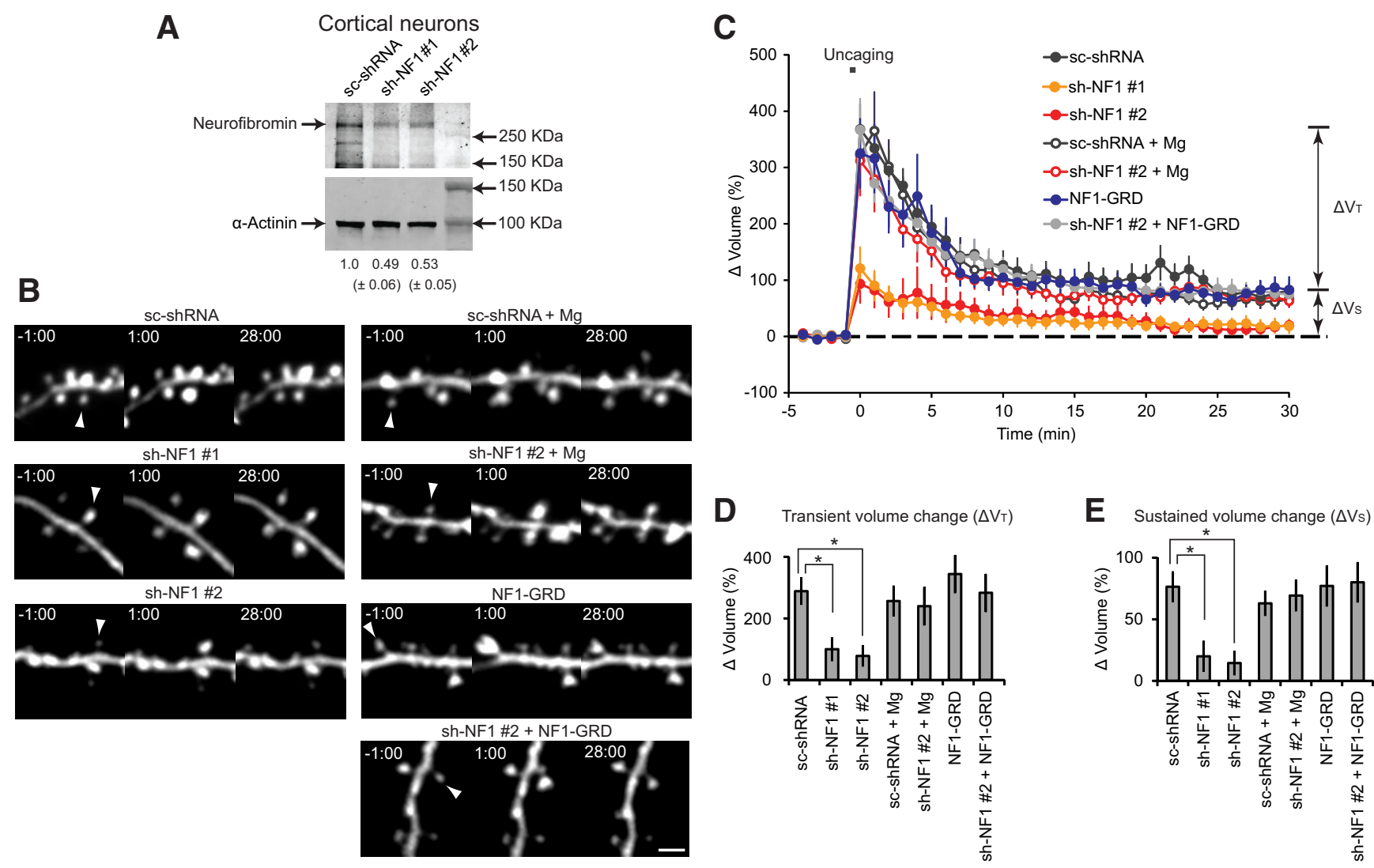

Figure 1. Knock-down of neurofibromin impairs spine enlargement after LTP induction in an activity- and Ras-dependent manner. $A$, Validation of shRNAs against neurofibromin. Knock-down of endogenous neurofibromin in PO cortical neuronal primary cultures infected with lentivirus containing sc-shRNA or shRNA targeted to neurofibromin (sh-NF1 \#1 and sh-NF1 \#2) for $7 \mathrm{~d}$. $\alpha$-Actinin was used as a loading control. Neurofibromin levels were detected by immunoblotting. $\boldsymbol{B}$, Representative images of spine structural plasticity in secondary or tertiary apical dendrites of CA1 pyramidal neurons expressing sc-shRNA, sh-NF1\#1, sh-NF1 \#2, or NF1-GRD. Some neurons (indicated with " $+\mathrm{Mg}^{\prime \prime}$ ) were treated with $10 \mathrm{~mm} \mathrm{MgCl}$ for $6-7 \mathrm{~d}$ during expression of shRNAs. Uncaging experiments were performed in the absence of $\mathrm{Mg}^{2+}$. White arrows indicate stimulated spines. Scale bar, $3 \mu \mathrm{m}$. C, Time course of spine volume change in response to glutamate uncaging. $\boldsymbol{D}, \boldsymbol{E}$, Quantification of the stimulated spine volume during the transient phase $(\boldsymbol{D})$ and sustained phase $(\boldsymbol{E})$ of spine enlargement. The number of neurons is as follows: 17 (sc-shRNA), 11 (sh-NF1 \#1), 13 (sh-NF1 \#2), 8 (NF1-GRD), 15 (sh-NF1 \#2 + Mg), 14 (sc-shRNA + Mg), and 9 (sh-NF1 \#2 + Mg); ${ }^{*} p<0.05$ compared with control, ANOVA and Fischer's least significant difference tests.

error bars in figures indicate SEM. The errors of Ras decay rates were estimated by bootstrapping.

DNA constructs. Short hairpin RNA (shRNA) targeted to rat neurofibromin (sh-NF1) or a scrambled shRNA (sc-shRNA) were cloned into a plasmid consisting of a dual promoter $\mathrm{CMV}$-enhanced green fluorescent protein (EGFP)/U1-shRNA vector (pGeneClip) or the pLL3.8 vector (also a dual promotor vector CMV-EGFP/U6-shRNA). When necessary, EGFP was removed from the pLL3.8 vector. cDNA of the GAP-related domain from neurofibromin isoform I (NF1-GRD) was obtained from Dr. Fuyuhiko Tamanoi (University of California, Los Angeles, CA) through Addgene and inserted into the pCI vector. The fluorescence resonance energy transfer (FRET)/fluorescence lifetime imaging (FLIM) Ras sensor FRas-2M consists of two constructs: HRas fused to monomeric EGFP in pCI vector (pCI-mEGFP-HRas) and the Ras-binding domain of Raf1 with the mutations K65E and K108A fused to two monomeric red fluorescent proteins on its terminals in pCI vector (pCI-mRFPRBD $^{\text {K65E,K108A }}$-mRFP; Yasuda et al., 2006; Oliveira and Yasuda, 2013).

Cell culture and transfection. For shRNA validation, cortical dissociated neurons were prepared from Sprague Dawley rats of either sex at postnatal day 0 (P0) and cultured on $35 \mathrm{~mm}$ dishes coated with poly-Dlysine as described previously (McDowell et al., 2010).

Lentivirus and infection. Lentivirus packaged with pLL3.8 harboring shRNA and EGFP was generated by the Duke University Neurotransgenic Laboratory, which is supported in part by funding from the National Institutes of Health-National Institute of Neurological Disorders and Stroke Center (Core Grant 5P30NS061789). For the shRNA validation experiments, $\mathrm{P} 0$ cortical neuron cultures were infected with lentivirus at DIV 1-3. Cell lysates were collected 5-7 d later for immunoblot analysis.
Organotypic hippocampal slice cultures and transfection. Hippocampal slice cultures were prepared from P6 or P7 rats of either sex, as described previously (Stoppini et al., 1991), in accordance with the animal care and use guidelines of the Duke University Medical Center. After 10-15 d in culture, CA1 pyramidal neurons were transfected with ballistic gene transfer (O'Brien and Lummis, 2006) using a Helios gene gun (Bio-Rad). Bullets were prepared using $8-11 \mathrm{mg}$ of $1.6 \mu \mathrm{m}$ gold particles (Bio-Rad) coated with a total of $50 \mu \mathrm{g}$ of plasmids containing cDNA. For experiments using the Ras sensor, we used $10 \mu \mathrm{g}$ of either sc-shRNA, sh-NF1 or NF1-GRD together with $10 \mu \mathrm{g}$ of pCI-mEGFP-HRas and $30 \mu \mathrm{g}$ of pCI-mRFP-RBD ${ }^{\mathrm{K} 65 \mathrm{E}, \mathrm{K} 108 \mathrm{~A}}$ mRFP. For pharmacological experiments, the respective drug $\left(\mathrm{MgCl}_{2}\right.$ or AP5) was added to the culture medium at the time of transfection and kept in the culture medium until the experiment was performed. Imaging was performed 5-7 d after transfection at room temperature $\left(\sim 25^{\circ} \mathrm{C}\right)$.

Western blot. Five to seven days after lentivirus infection, neurons were lysed in lysis buffer (50 mm Tris-HCl, 1 mm EDTA, 1 mm EGTA, $150 \mathrm{~mm}$ $\mathrm{NaCl}, 1 \%$ Triton X-100, pH 7.4) containing a protease inhibitor mixture (Roche; Wang et al., 2008). The lysates were cleared by centrifugation and protein concentrations were measured by BCA assays (Pierce) and subjected to immunoblotting. Primary antibodies used in the study included the following: rabbit anti-neurofibromin 1:500 (sc-68; Santa Cruz Biotechnology) and mouse anti- $\alpha$ actinin 1:5000 (612576; BD Biosciences). The secondary antibodies used for detection were CF680 goat anti-mouse IgG (20065; Biotium) and CF770 goat anti-rabbit IgG (20078; Biotium). Signals were visualized with fluorescence detection systems (Odyssey; Li-Cor).

mEPSC recording. Miniature EPSC (mEPSC) recording was performed in CA1 pyramidal neurons in organotypic hippocampal slices in artificial CSF (ACSF) containing the following (in mM): $127 \mathrm{NaCl}, 2.5$ 
A untransf. Uncaging

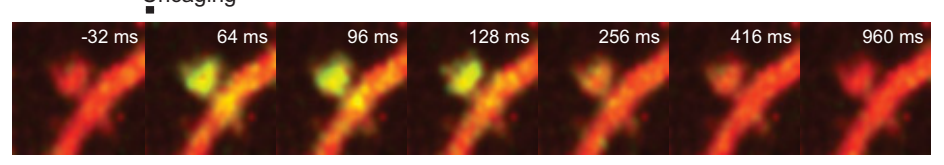

sh-NF1 Uncaging

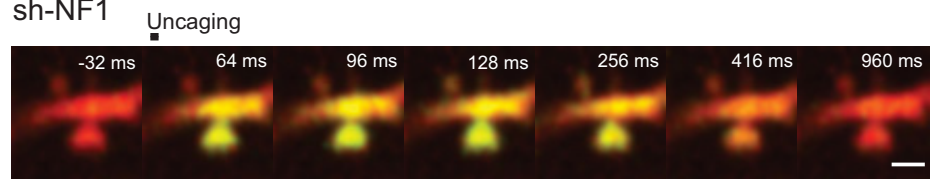

B

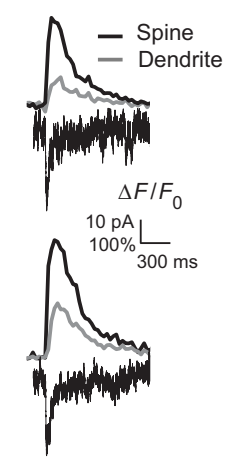

C

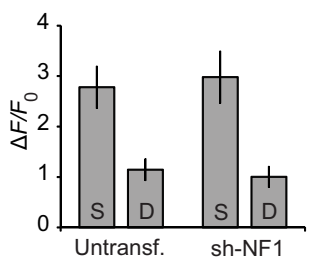

D

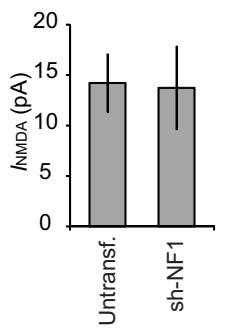

Figure 2. Neurofibromin regulates neither the NMDAR current $\left(/_{\text {NMDAR }}\right)$ nor $\left(a^{2+}\right.$ permeability. $A$, Representative images of spines from neurons filled with a red-insensitive dye (Alexa Fluor 594 ) and a green $\mathrm{Ca}^{2+}$-sensitive dye (Oregon Green BAPTA-5N), before and upon stimulation. Scale bar, $2 \mu \mathrm{m}$. B, Representative electrophysiological traces of $I_{\text {NMDAR }}$ measured at the soma upon uncaging stimulation paired with the respective traces for $\mathrm{C}^{2+}$ elevation in the spine and adjacent dendrite. $C$, Quantification of the peak fluorescence normalized to baseline fluorescence in the stimulated dendritic spines (S) and their adjacent dendrites ( $D ; n=9$ for untransfected neurons or $n=7$ for sh-NF1 neurons). $\boldsymbol{D}$, Quantification of the peak $I_{\text {NMDAR, }}$ in pA measured at the soma.

$\mathrm{KCl}, 25 \mathrm{NaHCO}_{3}, 1.25 \mathrm{NaH}_{2} \mathrm{PO}_{4}, 4 \mathrm{CaCl}_{2}, 25 \mathrm{D}$-glucose plus the following (in $\mu \mathrm{M}$ ): 20 bicuculline, 0.5 tetrodotoxin (TTX), 20 mibefradil, 100 picrotoxin, 20 nimodipine, and $50 \mathrm{AP} 5$ using $\mathrm{Cs}^{+}$-based internal solution containing the following (in $\mathrm{mm}$ ): $100 \mathrm{CsCH}_{3} \mathrm{SO}_{3}, 20 \mathrm{CsCl}, 10 \mathrm{Cs}-$ HEPES, 10 Cs-EGTA, $4 \mathrm{MgCl}_{2}, 0.4 \mathrm{Na}_{2} \mathrm{GTP}, 4 \mathrm{MgATP}$, and $10 \mathrm{Na}$ phosphocreatine (Shankar et al., 2007). Recordings were made using a Multiclamp 700B amplifier under voltage-clamp mode with a holding potential $\left(V_{\text {hold }}\right)$ of $-70 \mathrm{mV}$. The signal was filtered at $2 \mathrm{kHz}$ and digitized at $10 \mathrm{kHz}$ with a data acquisition board (PCI-6040e; National Instruments). Five sets of $60 \mathrm{~s}$ recordings (total $300 \mathrm{~s}$ ) were performed from each neuron. The amplitude and frequency of mEPSCs were analyzed in MATLAB using a template matching with detection criteria that included an amplitude $>8 \mathrm{pA}$, a minimum rise rate of $5 \mathrm{pA} / \mathrm{ms}$, and a decay constant between 1 and $12 \mathrm{~ms}$ (Clements and Bekkers, 1997).

Two-photon fluorescence microscopy and 2pFLIM. Imaging experiments were performed under a custom-built two-photon microscope equipped with a fluorescence lifetime imaging system with two Ti:sapphire pulsed lasers (MaiTai; Spectra-Physics). One of the lasers was tuned to $920 \mathrm{~nm}$ for imaging fluorescent proteins and the other one was tuned to $720 \mathrm{~nm}$ for glutamate uncaging. The intensity of each laser beam was independently controlled with electro-optical modulators (350-80 LA; Conoptics). The two laser beams were combined using a beam-splitting cube and passed through the same set of galvano-scanning mirrors and objective $(60 \times, 0.9$ numerical aperture; Olympus). Emitted fluorescence was divided with a dichroic mirror (565 nm; Chroma) and detected with photomultiplier tubes (H7422-40 for green and R3896 for red; Hamamatsu) after wavelength filters (HQ510/70-2p for green and HQ620/90 -2p for red; Chroma Technology). Fluorescence intensity images were acquired by ScanImage (Pologruto et al., 2003) using a data acquisition board (PCI-6110; National Instruments) and fluorescence lifetime images were acquired with a time-correlated single photon counting system (SPC-150; Becker and Hickl). Binding fraction was calculated as described previously (Yasuda et al., 2006; Oliveira and Yasuda, 2013).

Two-photon glutamate uncaging and spine enlargement. Spine structural plasticity was induced with 2-photon glutamate uncaging ( 30 pulses at $5 \mathrm{~mW}$ with $6 \mathrm{~ms}$ duration at $0.5 \mathrm{~Hz}$ ) in $\mathrm{Mg}^{2+}$-free ACSF containing the following (in mM): $127 \mathrm{NaCl}, 2.5 \mathrm{KCl}, 25 \mathrm{NaHCO}_{3}, 1.25 \mathrm{NaH}_{2} \mathrm{PO}_{4}, 4$ $\mathrm{CaCl}_{2}$, and 25 D-glucose plus $1 \mu \mathrm{M}$ TTX and $2 \mathrm{~mm}$ 4-methoxy-7nitroindolinyl-caged-L-glutamate (MNI-glutamate) aerated with $95 \%$ $\mathrm{O}_{2}$ and $5 \% \mathrm{CO}_{2}$. The changes in spine volume were quantified by the fractional change in fluorescence light intensity of EGFP. The sustained volume change was calculated as the mean volume at $25 \mathrm{~min}$ to $30 \mathrm{~min}$ minus the mean baseline normalized to the baseline volume. The transient volume change was calculated as the difference between the mean peak volume at $\sim 1 \mathrm{~min}$ after uncaging and the sustained phase normalized to the baseline volume.
Calcium imaging. CA1 pyramidal neurons transfected with mRFP together with shRNA (or their neighboring cells) were subjected to the measurement of $\left[\mathrm{Ca}^{2+}\right]$ elevation in dendritic spines and whole-cell current evoked by glutamate uncaging (Yasuda et al., 2004). Whole-cell patch clamp was performed with pipettes $\left(4-5 \mathrm{M} \Omega\right.$ ) containing $\mathrm{Cs}^{+}{ }_{-}$ based internal solution plus a red $\mathrm{Ca}^{2+}$-insensitive dye $(300 \mu \mathrm{M}$ Alexa Fluor 594; Invitrogen) and a green $\mathrm{Ca}^{2+}$-sensitive dye (500 $\mu \mathrm{M}$ OregonGreen-BAPTA 5N, OGB-5N; Invitrogen) in $\mathrm{Mg}^{2+}$-free ACSF plus $1 \mu \mathrm{M}$ TTX, 2 mM MNI-glutamate, and $20 \mu \mathrm{M}$ NBQX (Noguchi et al., 2005). After loading neurons with the dyes for $>20 \mathrm{~min}$, images of dendritic spines were acquired every $32 \mathrm{~ms}$ under a two-photon microscope while uncaging MNI-glutamate. Each trial started with the measurement of the dark current of the photomultiplier (two frames) followed by shutter opening. After measurement of baseline fluorescence (12 frames), a glutamate uncaging pulse $(6 \mathrm{~ms}, 4-5 \mathrm{~mW})$ was applied. Uncaging-evoked $\mathrm{Ca}^{2+}$ transients were measured as $\left(F-F_{0}\right) / F_{0}$, where $F$ and $F_{0}$ are the fluorescence signals during the response and baseline periods, respectively. Simultaneously, uncaging evoked postsynaptic currents (uEPSCs) were recorded from the soma under a voltage clamp $\left(V_{\text {hold }}=-70 \mathrm{mV}\right)$ using a Multiclamp 700B amplifier, filtered at $2 \mathrm{kHz}$, and acquired at $10 \mathrm{kHz}$. For each spine, the recordings of $\mathrm{Ca}^{2+}$ transients and uEPSCs were repeated $\sim 10$ times with $15 \mathrm{~s}$ intervals and the data were averaged over the trials.

\section{Results}

To examine the function of neurofibromin in plasticity of dendritic spines, we transiently knocked down neurofibromin using shRNA targeted to different sequences of neurofibromin (shNF1 \#1 and \#2; 6-7 d) in CA1 pyramidal neurons (Fig. 1) and induced structural plasticity in single dendritic spines using twophoton glutamate uncaging. Spine structural plasticity is thought to be essential for the induction and expression of LTP (Matsuzaki et al., 2004), learning, and memory (Kim et al., 2013). We monitored spine volume using fluorescence of EGFP coexpressed with shRNA. In control neurons expressing scrambled shRNA (sc-shRNA), the stimulated dendritic spine displayed a rapid increase in volume within $\sim 1$ min after the stimulation (transient phase; Fig. $1 B-D$ ), and then the spine volume decayed over $\sim 5 \mathrm{~min}$ to a smaller sustained enlargement that was maintained for $>30 \mathrm{~min}$ (sustained phase; Fig. $1 B, C, E$ ). This time course of spine structural plasticity is similar to that observed in previous studies (Matsuzaki et al., 2004; Harvey and Svoboda, 2007; Lee et al., 2009; Murakoshi et al., 2011). In contrast, in neurons transfected with sh-NF1s, spine structural plasticity was significantly impaired during both transient and sustained phases (Fig. $1 B-E$ ). Overexpression of the GAPrelated domain of neurofibromin (NF1-GRD; RasGAP domain) by 


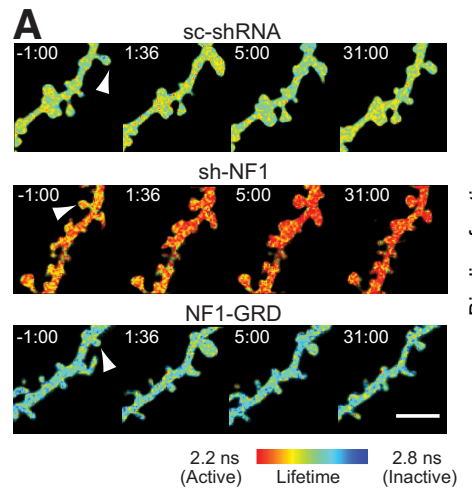

B
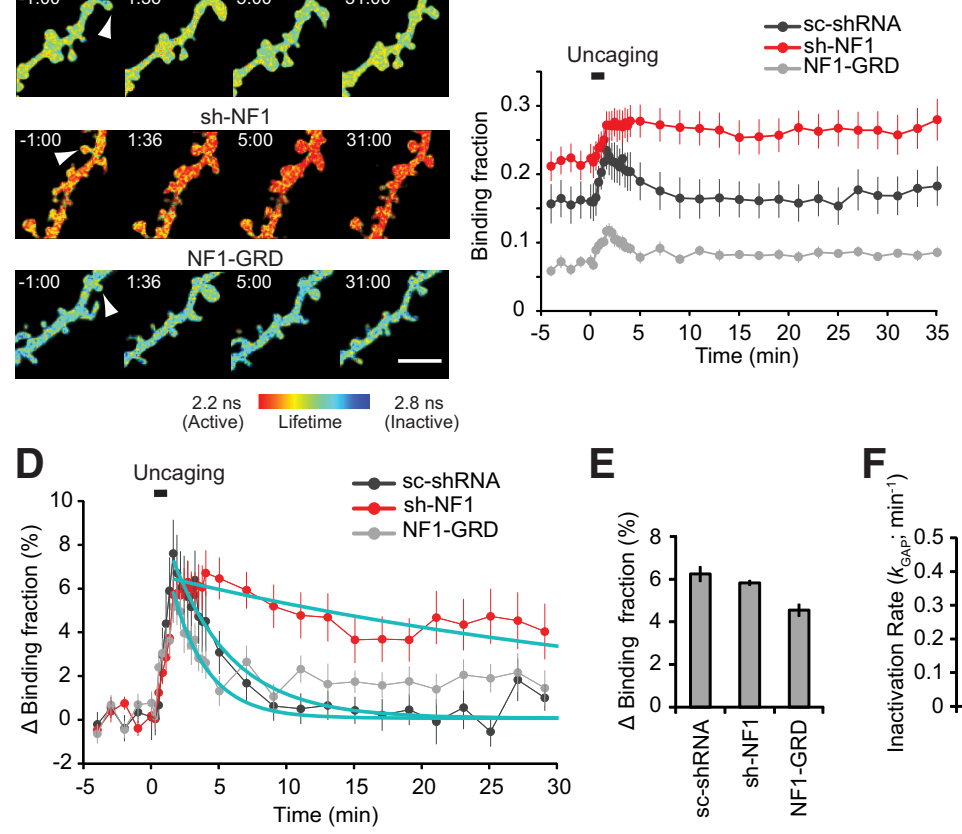

G
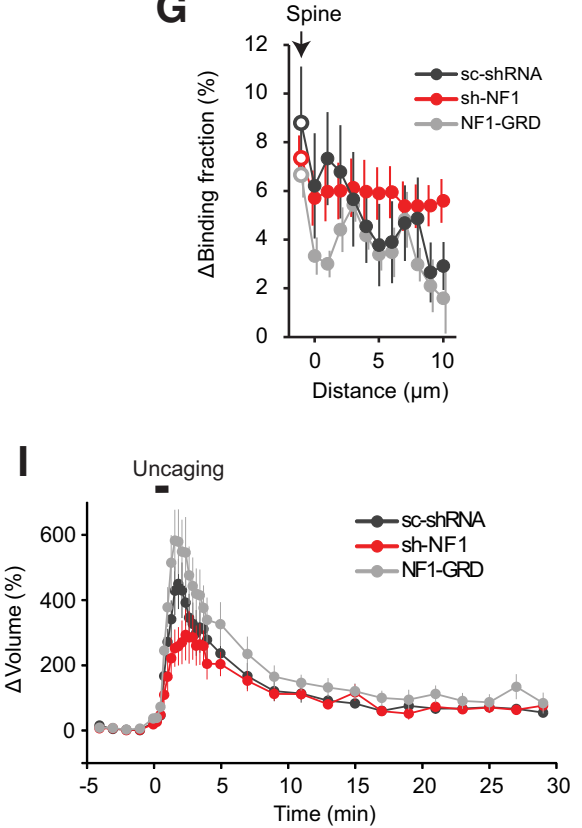

E

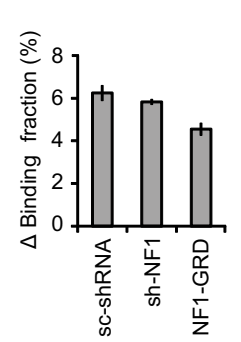

H

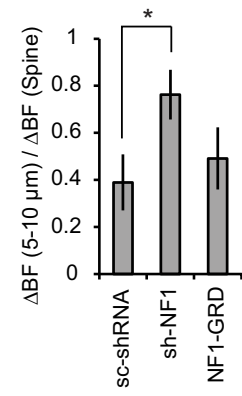

$J$

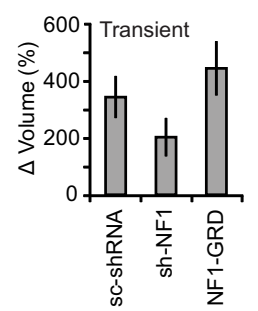

Figure 3. Neurofibromin inactivates Ras in dendritic spines. $\boldsymbol{A}$, Pseudocolor FLIM images of Ras activity in CA1 pyramidal neurons transfected with the Ras sensor together with sc-shRNA, sh-NF1\#2 or NF1-GRD and treated with $10 \mathrm{~mm} \mathrm{MgCl}$ for $6-7 \mathrm{~d}$. Uncaging experiments were performed in the absence of $\mathrm{Mg}^{2+}$. White arrows indicate stimulated spines. Scale bar, $4 \mu \mathrm{m}$. $\boldsymbol{B}$, Time course of Ras activation in the stimulated spines. C, Basal Ras activity (before stimulation). $\boldsymbol{D}$, Time course of Ras activation in the stimulated spine ( $\boldsymbol{B}$ subtracted by $\boldsymbol{C}$ ). Blue curves indicate exponential decay curves fitted to the data. $\boldsymbol{E}$, Quantification of Ras activation: peak Ras activation was obtained by averaging the change in binding fraction over $64-160 \mathrm{~s}$. $\boldsymbol{F}$, Ras inactivation rate was measured from the fitting curves in $\boldsymbol{D}$. G, Spatial profile of Ras activation at the time points in which Ras activation peaks in the stimulated spines ( $66-80 \mathrm{~s}$ for sc-shRNA and NF1-GRD and 5-7 min for sh-NF1). Open circles indicate the activity in the stimulated spine and filled circles indicate the activity in the dendrite plotted as a function of the distance along the dendrite from the stimulated spine. We selected data in which $>10 \mu \mathrm{m}$ of the dendritic segment is in focus and Ras activation in spines is $>3 \%$ at the peak. $\boldsymbol{H}$, Quantification of Ras spreading. Ras activation along the dendrite (5-10 $\mu \mathrm{m})$ was normalized to Ras activation in the stimulated spine at the time points in which Ras activation peaks in the stimulated spines. ${ }^{*} p<0.05$ compared with control. $I$, Time course of spine volume change in neurons expressing the Ras sensor. $\boldsymbol{J}-\boldsymbol{K}$, Quantification of spine structural plasticity: transient volume change $(\boldsymbol{J})$ and sustained volume change $(\boldsymbol{K})$. Number of neurons is 12 (sc-shRNA), 13 (sh-NF1), 10 (NF1-GRD), or 9 for all conditions in $\boldsymbol{G}-\boldsymbol{H}$. ${ }^{*} p<0.05$ compared with control. itself did not cause any effects on structural plasticity, but rescued structural plasticity when coexpressed with sh-NF1 (Fig. 1B-E). These data suggest that Ras inactivation by neurofibromin is required for normal spine structural plasticity. Although neurofibromin is reported to interact with the NMDAR (Husi et al., 2000), we did not observe any effect of sh-NF1 on NMDARdependent postsynaptic current and $\mathrm{Ca}^{2+}$ elevation induced by two-photon glutamate uncaging (Fig. 2). Therefore, the phenotype in spine structural plasticity appears to be not due to a change in NMDAR-evoked $\mathrm{Ca}^{2+}$ elevation, but rather to be caused by a change in Ras signaling.

Given that Ras is activated by spontaneous neuronal activity (Zhu et al., 2002), we further tested whether the impairment of spine plasticity depends on spontaneous neuronal activity by culturing slices in the presence of high $\mathrm{Mg}^{2+}(10 \mathrm{~mm})$ during expression of sh-NF1 (Zhu et al., 2000; Harvey et al., 2008). It has been reported that high $\mathrm{Mg}^{2+}$ inhibits circuit activity in organotypic slice cultures (Zhu et al., 2000) and significantly reduces Ras activation evoked by spontaneous neuronal activity (Zhu et al., 2002; Harvey et al., 2008). Under this condition, the impairment of spine enlargement by neurofibromin knock-down was rescued, indicating that the phenotype is due to spontaneous neuronal activity (Fig. $1 B-E$ ). These results suggest that the impaired spine plasticity in neurons expressing sh-NF1 is due to reduced inactivation of Ras evoked by spontaneous neuronal activity (Zhu et al., 2000; Zhu et al., 2002).

To further address to what degree neurofibromin contributes to Ras inactivation in single dendritic spines, we downregulated neurofibromin with sh-NF1 and imaged Ras activity with a FRET/FLIM Ras activation sensor, FRas2-M (Harvey et al., 2008; Oliveira and Yasuda, 2013). Because spontaneous network activity in the culture decreases the sensitivity of the Ras sensor and inhibits spine structural plasticity in the presence of sh-NF1 (Fig. 1), we inhibited spontaneous network activity during expression of the sensor and shRNA with high $\mathrm{Mg}^{2+}$ (10 mm; Zhu et al., 2000; Zhu et al., 2002; Harvey et al., 2008). Consistent with the results obtained with GFP-expressing neurons (Fig. 1), sh-NF1 did not impair spine structural plasticity in neurons expressing the Ras sensor under this condition (Figs. 1, 3I-K).

In control neurons, when 2-photon glutamate uncaging was applied near a single spine, Ras activity was rapidly increased within $\sim 1 \mathrm{~min}$ in the stimulated 
spine and decayed over $\sim 10$ min (Fig. $3 A, B, D)$. The decay kinetics was consistent with that measured with a Ras sensor with lower affinity (FRas-F; Harvey et al., 2008). In neurons expressing sh-NF1, the basal Ras activity in dendritic spines was higher (Fig. 3C), and, after glutamate uncaging, Ras was activated to a similar level to the control condition. However, Ras activation decayed much more slowly (Fig. 3D). Curve-fitting analyses indicate that the rate of Ras inactivation in neurons expressing sh-NF1 was only $\sim 10 \%$ of that in control neurons, whereas the peak amplitude of Ras activation did not show significant change (Fig. 3D-F). In contrast, in neurons expressing NF1GRD, the basal activity was lower (Fig. 3C) and, after single spine stimulation, Ras activity decayed faster than in control neurons (Fig. 3D,F). These data indicate that neurofibromin is the major Ras inactivator in dendritic spines and is required for rapid inactivation of Ras.

We further examined the spreading of Ras activation from the stimulated spines (Fig. 3G,H). Assuming that the activity spreading is caused by the diffusion of active Ras molecules before Ras is inactivated by GAPs, the spreading can be formulated as an exponential decay with the length constant $L$ as follows:

$$
L \sim\left(D / k_{\mathrm{GAP}}\right)^{1 / 2}
$$

where $D$ is the diffusion coefficient of Ras in the dendrite $(\sim 0.5$ $\mu \mathrm{m}^{2} / \mathrm{s}$ ) and $k_{\mathrm{GAP}}$ is the rate constant of Ras inactivation (Harvey et al., 2008; Murakoshi et al., 2011). If neurofibromin is the major Ras inactivator in dendritic spines, then loss of neurofibromin should cause wider Ras spreading. Indeed, we observed Ras spreading consistent with this hypothesis: in control neurons expressing sc-shRNA, Ras activity diffuses out of the stimulated spines and spreads over $\sim 10 \mu \mathrm{m}$ along the dendritic shaft, consistent with a previous study (Harvey et al., 2008; Fig. 3G). However, the spatial decay of Ras in neurons expressing sh-NF1 was largely abolished (Fig. 3G). To further quantify the degree of the Ras activity spreading, we measured Ras activation in the dendritic shaft over 5-10 $\mu \mathrm{m}$ from the stimulated spines normalized to Ras activation in the spine (Fig. $3 H$ ). The value was significantly higher in neurons expressing sh-NF1 compared with control neurons, indicating that loss of neurofibromin leads to larger Ras spreading. In contrast, we did not observe significant differences for neurons expressing NF1-GRD, presumably because twofold higher $k_{\mathrm{GAP}}$ (Fig. $3 F$ ) is expected to change $L$ only by $\sim 30 \%$ (Equation 1 ).

We further examined whether the impaired structural plasticity and Ras inactivation in neurons with reduced level of neurofibromin cause long-term effects on the dendritic morphology (Fig. 4). Neurons expressing sh-NF1 showed reduced spine density after 5-7 d of transfection and the phenotype was rescued by overexpressing NF1-GRD or a dominant-negative Ras (Fig. $4 A, B$ ). In addition, inhibition of NMDARs with AP5 $(100 \mu \mathrm{M})$ or neuronal activity with $\mathrm{MgCl}_{2}(10 \mathrm{~mm})$ in the medium during the culture re-
B

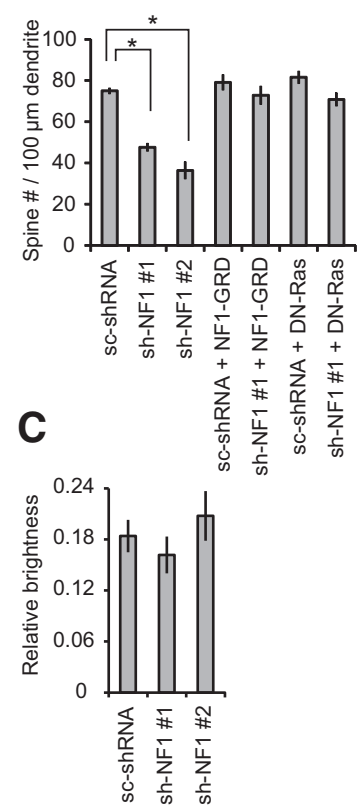

D
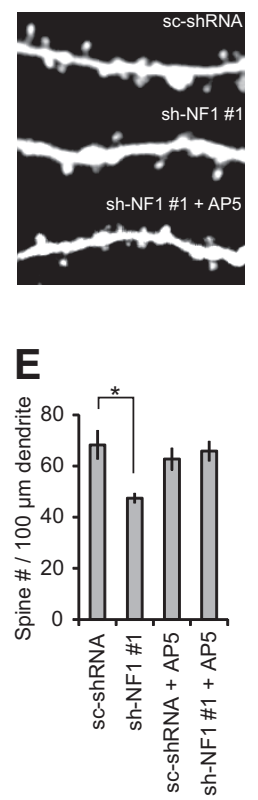

$\mathbf{F}$

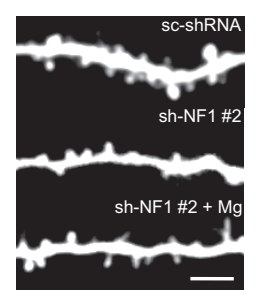

G

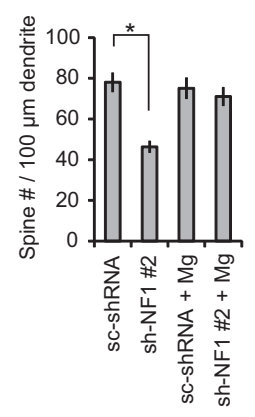

Figure 4. Neurofibromin regulates the spine density in a Ras- and activity-dependent manner. $\boldsymbol{A}, \mathbf{D}, \boldsymbol{F}$, Representative images of segments of secondary and tertiary apical dendrites of neurons transfected with indicated constructs for $5-7 \mathrm{~d}$. Some neurons shRNA + AP5), and 42/11 (sh-NF1\#1 + AP5). The number of dendrites/neurons shown in G is as follows: 25/11 (sc-shRNA), 29/12 (sh-NF1 \#2), 17/10 (sc-shRNA + Mg), and 36/15 (sh-NF1\#2 + Mg). ${ }^{*} p<0.05$ compared with control.

stored normal spine density (Fig. 4D-G). We observed no effects of sh-NF1 expression on the relative volume of dendritic spines, measured as fluorescence intensity within the spine normalized to that in the thick primary dendrite (Fig. $4 C$ ). These results suggest that hyperactivation of the NMDAR-Ras pathway due to knock-down of neurofibromin results in spine loss.

In hippocampal pyramidal neurons, each dendritic spine is normally associated with one glutamatergic synapse and the majority of excitatory synapses form onto dendritic spines (Harris and Stevens, 1989). Therefore, changes in spine number are thought to reflect changes in the number of functional excitatory synapses. Consistent with this hypothesis, we observed reduced frequency of mEPSCs in neurons expressing sh-NF1 compared with untransfected neurons or with neurons expressing scshRNA (Fig. $5 A, B$ ). Conversely, the amplitude of mEPSCs was similar between control neurons and those expressing sh-NF1 (Fig. 5A,C). Therefore, these results suggest that neurofibromin plays an important role in the maintenance of spine structure by inactivating Ras rapidly.

\section{Discussion}

The results of our study revealed that neurofibromin is responsible for the majority of Ras inactivation in dendritic spines in response to NMDAR activation and a lack of Ras inactivation in neurons expressing low levels of neurofibromin leads to impaired structural plasticity and spine loss in an activity-dependent manner.

Our results indicated that induction of uncaging-evoked spine structural plasticity, a form of plasticity presumably solely dependent on postsynaptic mechanisms, is inhibited when neu- 
A

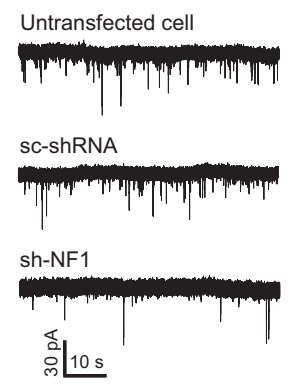

B

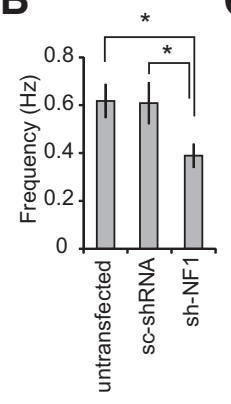

C

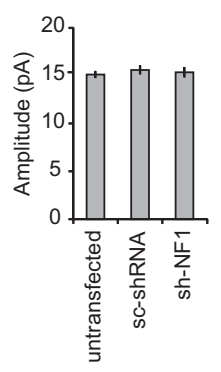

Figure 5. Neurofibromin regulates the number of functional excitatory synapses. $A$, Representative traces of $\mathrm{mEPSC}$ recorded at a holding potential of $-70 \mathrm{mV}$. $\boldsymbol{B}-\boldsymbol{C}$, Quantification of the frequency $(\boldsymbol{B})$ and amplitude $(\boldsymbol{C})$ of the mEPSCs recorded. Number of neurons: 53 (untransfected), 42 (sc-shRNA), and 45 (sh-NF1). ${ }^{*} p<0.05$ compared with control.

rofibromin is downregulated for a few days (Fig. 1). This form of spine plasticity is associated with increased postsynaptic glutamate sensitivity (Matsuzaki et al., 2004) and shares similar pharmacological properties with LTP (Matsuzaki et al., 2004; Harvey et al., 2008; Murakoshi et al., 2011). Therefore, spine enlargement is thought to be one of the mechanisms underlying LTP induction and expression (Matsuzaki et al., 2004; Harvey et al., 2008; Lee et al., 2009; Murakoshi et al., 2011). Further, inhibiting structural plasticity of spines by modifying actin association proteins in pyramidal neurons causes memory impairment (Kim et al., 2013). Therefore, although a previous study suggested that hyperactivation of Ras in interneurons contributes to learning deficits in Nf1-heterozygous knock-out mice (Cui et al., 2008), our results indicate that neurofibromin in dendritic spines of pyramidal neurons also plays a significant role in regulating synaptic plasticity and likely learning and memory. Moreover, we found that the impairment of structural plasticity is dependent on Ras signaling, because the RasGAP domain of neurofibromin (NF1GRD), which represents a relatively small portion of the whole protein $(\sim 10 \%)$, can rescue the effect of sh-NF1 (Fig. 1). Besides Ras, NF1-GRD can also interact with syndecan-2 and the interaction is reported to be necessary for cAMP signaling transduction (Hsueh et al., 2001; Lin et al., 2007). However, cAMP signaling additionally requires the $\mathrm{AC}$ interaction domain of neurofibromin (Hannan et al., 2006; Lin et al., 2007). NF1-GRD is considered to mainly act on the Ras signaling pathway (Ballester et al., 1990; Martin et al., 1990; Xu et al., 1990; Bollag et al., 1996; Hiatt et al., 2001). Therefore, our results suggest that hyperactivation of Ras in dendritic spines is involved in impaired synaptic plasticity. These results are consistent with previous studies reporting the important role of RasGAP function of neurofibromin in LTP and learning and memory (Costa et al., 2002; Li et al., 2005; Guilding et al., 2007).

Our FRET/FLIM Ras imaging demonstrated that Ras inactivation is largely abolished by decreasing the expression of neurofibromin (Fig. 3). This finding suggests that, among several RasGAPs identified in neurons, neurofibromin is the major Ras inactivation factor in spines. For example, SynGAP is highly accumulated in spines and has RasGAP activity (Chen et al., 1998; Kim et al., 1998). However, it has been found that SynGAP acts more strongly as a GAP toward Rap (Krapivinsky et al., 2004), a molecule of the Ras family important for LTD (Zhu et al., 2002). The roles of other RasGAPs in spines are less characterized, but our results suggest that neurofibromin may be the only RasGAP that inactivates NMDAR-evoked Ras activation.

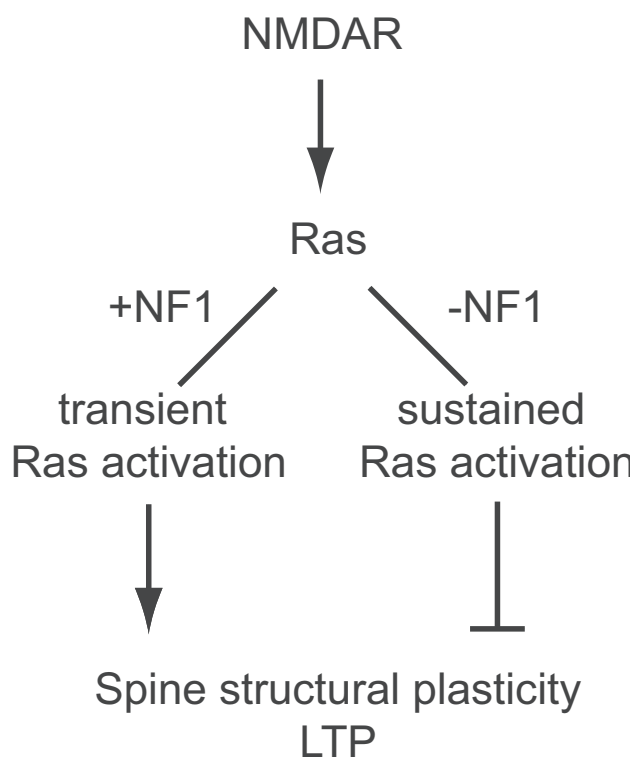

Figure 6. Hypothetical scheme linking the role of the duration of Ras activation and spine structural plasticity.

Ras activity imaging also revealed that neurofibromin is important for shaping Ras activity spreading (Fig. $3 G, H$ ). When Ras inactivation rate is low due to a reduced level of neurofibromin, Ras activity spreads more because Ras molecules can diffuse longer distances before they are inactivated (Fig. $3 G, H$ ). This may cause more spreading in potential downstream effects of the Ras pathway, such as exocytosis of AMPARs, priming of LTP, and priming of spinogenesis (Harvey and Svoboda, 2007; Harvey et al., 2008; Patterson et al., 2010; Kwon and Sabatini, 2011).

Our results also indicate that reducing the neurofibromin level leads to spine loss in an NMDAR-, Ras-, and activitydependent manner (Fig. 4). This is likely due to the long-term consequence of impaired spine structural plasticity (Fig. 1; Kasai et al., 2010). It has been reported previously that neurofibromin regulates spine formation through the CAMP pathway by activating AC in early development (Lin et al., 2007). However, in juvenile neurons in the organotypic slices we used, Ras inactivation by neurofibromin appears to be required for maintaining normal spine plasticity and density. Because impaired structural plasticity and loss of spines in neurons expressing sh-NF1 depend on spontaneous neuronal activity and on NMDAR and Ras activity (Figs. 1, 4), our results suggest that these phenotypes are caused by activation of the NMDAR-Ras pathway evoked by spontaneous neuronal activity (Zhu et al., 2000; Zhu et al., 2002).

It has been demonstrated that Ras activation is required for LTP induction and associated spine enlargement (Zhu et al., 2002; Harvey et al., 2008). This is apparently contradictory to our results indicating that prolonged Ras activation by downregulation of neurofibromin leads to impaired structural plasticity and spine loss in an activity-dependent manner. One possible mechanism is that Ras hyperactivation saturates synaptic potentiation and thereby prevents synapses from further potentiation. Alternatively, Ras signaling may activate different downstream pathways depending on its kinetics and prolonged Ras activation may activate an additional pathway leading to impaired spine enlargement and spine loss (Fig. 6). Because the saturation of synaptic potentiation unlikely leads to the spine loss and decreased mEPSC frequency that we observed (Figs. 4, 5), the second mechanism, namely signal activation dependent on the duration of Ras 
activation, appears to be responsible for impaired spine structural plasticity and spine loss. Ras signaling is known to activate different downstream targets depending on the duration of its activation in other systems. In PC12 cells, different growth factors cause different durations of Ras-ERK activation, leading to different cell responses (Marshall, 1995). In addition, for another Ras superfamily protein, Racl, the transient expression of a constitutively active protein promotes spine growth and increased dendritic spine density, but prolonged activation leads to spine shrinkage and elimination (Hayashi-Takagi et al., 2010). Overall, our present results and those of others indicate that the duration of Ras signaling is critical for signaling decision.

In conclusion, among 10 RasGAPs (Mitin et al., 2005), neurofibromin is the major Ras inactivator in spines and is important for long-term stability of spine morphology and function. These postsynaptic effects may be related to the learning disabilities commonly seen in NF1 patients.

\section{References}

Ballester R, Marchuk D, Boguski M, Saulino A, Letcher R, Wigler M, Collins F (1990) The NF1 locus encodes a protein functionally related to mammalian GAP and yeast IRA proteins. Cell 63:851-859. CrossRef Medline

Bollag G, Clapp DW, Shih S, Adler F, Zhang YY, Thompson P, Lange BJ, Freedman MH, McCormick F, Jacks T, Shannon K (1996) Loss of NF1 results in activation of the Ras signaling pathway and leads to aberrant growth in haematopoietic cells. Nat Genet 12:144-148. CrossRef Medline

Chen HJ, Rojas-Soto M, Oguni A, Kennedy MB (1998) A synaptic RasGTPase activating protein (p135 SynGAP) inhibited by CaM kinase II. Neuron 20:895-904. CrossRef Medline

Clements JD, Bekkers JM (1997) Detection of spontaneous synaptic events with an optimally scaled template. Biophys J 73:220-229. CrossRef Medline

Costa RM, Federov NB, Kogan JH, Murphy GG, Stern J, Ohno M, Kucherlapati R, Jacks T, Silva AJ (2002) Mechanism for the learning deficits in a mouse model of neurofibromatosis type 1. Nature 415:526-530. CrossRef Medline

Cui Y, Costa RM, Murphy GG, Elgersma Y, Zhu Y, Gutmann DH, Parada LF, Mody I, Silva AJ (2008) Neurofibromin regulation of ERK signaling modulates GABA release and learning. Cell 135:549-560. CrossRef Medline

Guilding C, McNair K, Stone TW, Morris BJ (2007) Restored plasticity in a mouse model of neurofibromatosis type 1 via inhibition of hyperactive ERK and CREB. Eur J Neurosci 25:99-105. CrossRef Medline

Guo HF, The I, Hannan F, Bernards A, Zhong Y (1997) Requirement of Drosophila NF1 for activation of adenylyl cyclase by PACAP38-like neuropeptides. Science 276:795-798. CrossRef Medline

Guo HF, Tong J, Hannan F, Luo L, Zhong Y (2000) A neurofibromatosis1-regulated pathway is required for learning in Drosophila. Nature 403: 895-898. CrossRef Medline

Hannan F, Ho I, Tong JJ, Zhu Y, Nurnberg P, Zhong Y (2006) Effect of neurofibromatosis type I mutations on a novel pathway for adenylyl cyclase activation requiring neurofibromin and Ras. Hum Mol Genet 15: 1087-1098. CrossRef Medline

Harris KM, Stevens JK (1989) Dendritic spines of CA 1 pyramidal cells in the rat hippocampus: serial electron microscopy with reference to their biophysical characteristics. J Neurosci 9:2982-2997. Medline

Harvey CD, Svoboda K (2007) Locally dynamic synaptic learning rules in pyramidal neuron dendrites. Nature 450:1195-1200. CrossRef Medline

Harvey CD, Yasuda R, Zhong H, Svoboda K (2008) The spread of Ras activity triggered by activation of a single dendritic spine. Science 321:136140. CrossRef Medline

Hayashi-Takagi A, Takaki M, Graziane N, Seshadri S, Murdoch H, Dunlop AJ, Makino Y, Seshadri AJ, Ishizuka K, Srivastava DP, Xie Z, Baraban JM, Houslay MD, Tomoda T, Brandon NJ, Kamiya A, Yan Z, Penzes P, Sawa A (2010) Disrupted-in-Schizophrenia 1 (DISC1) regulates spines of the glutamate synapse via Rac1. Nat Neurosci 13:327-332. CrossRef Medline

Hiatt KK, Ingram DA, Zhang Y, Bollag G, Clapp DW (2001) Neurofibromin GTPase-activating protein-related domains restore normal growth in Nf1 ${ }^{-1-}$ cells. J Biol Chem 276:7240-7245. CrossRef Medline

Hsueh YP, Roberts AM, Volta M, Sheng M, Roberts RG (2001) Bipartite interaction between neurofibromatosis type I protein (neurofibromin) and syndecan transmembrane heparan sulfate proteoglycans. J Neurosci 21:3764-3770. Medline

Husi H, Ward MA, Choudhary JS, Blackstock WP, Grant SG (2000) Proteomic analysis of NMDA receptor-adhesion protein signaling complexes. Nat Neurosci 3:661-669. CrossRef Medline

Kasai H, Fukuda M, Watanabe S, Hayashi-Takagi A, Noguchi J (2010) Structural dynamics of dendritic spines in memory and cognition. Trends Neurosci 33:121-129. CrossRef Medline

Kim IH, Racz B, Wang H, Burianek L, Weinberg R, Yasuda R, Wetsel WC, Soderling SH (2013) Disruption of Arp2/3 results in asymmetric structural plasticity of dendritic spines and progressive synaptic and behavioral abnormalities. J Neurosci 33:6081-6092. CrossRef Medline

Kim JH, Liao D, Lau LF, Huganir RL (1998) SynGAP: a synaptic RasGAP that associates with the PSD-95/SAP90 protein family. Neuron 20:683691. CrossRef Medline

Krapivinsky G, Medina I, Krapivinsky L, Gapon S, Clapham DE (2004) SynGAP-MUPP1-CaMKII synaptic complexes regulate p38 MAP kinase activity and NMDA receptor-dependent synaptic AMPA receptor potentiation. Neuron 43:563-574. CrossRef Medline

Kwon HB, Sabatini BL (2011) Glutamate induces de novo growth of functional spines in developing cortex. Nature 474:100-104. CrossRef Medline

Lee SJ, Escobedo-Lozoya Y, Szatmari EM, Yasuda R (2009) Activation of CaMKII in single dendritic spines during long-term potentiation. Nature 458:299-304. CrossRef Medline

Li W, Cui Y, Kushner SA, Brown RA, Jentsch JD, Frankland PW, Cannon TD, Silva AJ (2005) The HMG-CoA reductase inhibitor lovastatin reverses the learning and attention deficits in a mouse model of neurofibromatosis type 1. Curr Biol 15:1961-1967. CrossRef Medline

Lin YL, Lei YT, Hong CJ, Hsueh YP (2007) Syndecan-2 induces filopodia and dendritic spine formation via the neurofibromin-PKA-Ena/VASP pathway. J Cell Biol 177:829-841. CrossRef Medline

Manabe T, Aiba A, Yamada A, Ichise T, Sakagami H, Kondo H, Katsuki M (2000) Regulation of long-term potentiation by H-Ras through NMDA receptor phosphorylation. J Neurosci 20:2504-2511. Medline

Marshall CJ (1995) Specificity of receptor tyrosine kinase signaling: transient versus sustained extracellular signal-regulated kinase activation. Cell 80:179-185. CrossRef Medline

Martin GA, Viskochil D, Bollag G, McCabe PC, Crosier WJ, Haubruck H, Conroy L, Clark R, O'Connell P, Cawthon RM, Innis MA, McCormick F (1990) The GAP-related domain of the neurofibromatosis type 1 gene product interacts with ras p21. Cell 63:843-849. CrossRef Medline

Matsuzaki M, Honkura N, Ellis-Davies GC, Kasai H (2004) Structural basis of long-term potentiation in single dendritic spines. Nature 429:761-766. CrossRef Medline

McDowell KA, Hutchinson AN, Wong-Goodrich SJ, Presby MM, Su D, Rodriguiz RM, Law KC, Williams CL, Wetsel WC, West AE (2010) Reduced cortical BDNF expression and aberrant memory in Carf knock-out mice. J Neurosci 30:7453-7465. CrossRef Medline

Mitin N, Rossman KL, Der CJ (2005) Signaling interplay in Ras superfamily function. Curr Biol 15:R563-R574. CrossRef Medline

Murakoshi H, Wang H, Yasuda R (2011) Local, persistent activation of Rho GTPases during plasticity of single dendritic spines. Nature 472:100-104. CrossRef Medline

Noguchi J, Matsuzaki M, Ellis-Davies GC, Kasai H (2005) Spine-neck geometry determines NMDA receptor-dependent $\mathrm{Ca}^{2+}$ signaling in dendrites. Neuron 46:609-622. CrossRef Medline

O'Brien JA, Lummis SC (2006) Biolistic transfection of neuronal cultures using a hand-held gene gun. Nat Protoc 1:977-981. CrossRef Medline

Oliveira AF, Yasuda R (2013) An improved Ras sensor for highly sensitive and quantitative FRET-FLIM imaging. PLoS One 8:e52874. CrossRef Medline

Patterson MA, Szatmari EM, Yasuda R (2010) AMPA receptors are exocytosed in stimulated spines and adjacent dendrites in a Ras-ERKdependent manner during long-term potentiation. Proc Natl Acad Sci U S A 107:15951-15956. CrossRef Medline

Pologruto TA, Sabatini BL, Svoboda K (2003) ScanImage: flexible software for operating laser scanning microscopes. BioMed Eng OnLine 2.

Shankar GM, Bloodgood BL, Townsend M, Walsh DM, Selkoe DJ, Sabatini BL (2007) Natural oligomers of the Alzheimer amyloid-beta protein induce reversible synapse loss by modulating an NMDA-type glutamate receptor-dependent signaling pathway. J Neurosci 27:2866-2875. CrossRef Medline 
Silva AJ, Frankland PW, Marowitz Z, Friedman E, Laszlo GS, Cioffi D, Jacks T, Bourtchuladze R, Lazlo G (1997) A mouse model for the learning and memory deficits associated with neurofibromatosis type I. Nat Genet 15: 281-284. CrossRef Medline

Stoppini L, Buchs PA, Muller D (1991) A simple method for organotypic cultures of nervous tissue. J Neurosci Methods 37:173-182. CrossRef Medline

Stornetta RL, Zhu JJ (2011) Ras and Rap signaling in synaptic plasticity and mental disorders. Neuroscientist 17:54-78. CrossRef Medline

Thomas GM, Huganir RL (2004) MAPK cascade signalling and synaptic plasticity. Nat Rev Neurosci 5:173-183. CrossRef Medline

Wang HF, Shih YT, Chen CY, Chao HW, Lee MJ, Hsueh YP (2011) Valosincontaining protein and neurofibromin interact to regulate dendritic spine density. J Clin Invest 121:4820-4837. CrossRef Medline

Wang Z, Edwards JG, Riley N, Provance DW Jr, Karcher R, Li XD, Davison IG, Ikebe M, Mercer JA, Kauer JA, Ehlers MD (2008) Myosin Vb mobilizes recycling endosomes and AMPA receptors for postsynaptic plasticity. Cell 135:535-548. CrossRef Medline

Wu GY, Deisseroth K, Tsien RW (2001) Spaced stimuli stabilize MAPK pathway activation and its effects on dendritic morphology. Nat Neurosci 4:151-158. CrossRef Medline
Xu GF, O'Connell P, Viskochil D, Cawthon R, Robertson M, Culver M, Dunn D, Stevens J, Gesteland R, White R, Weiss R (1990) The neurofibromatosis type 1 gene encodes a protein related to GAP. Cell 62:599-608. CrossRef Medline

Yasuda R, Nimchinsky EA, Scheuss V, Pologruto TA, Oertner TG, Sabatini BL, Svoboda K (2004) Imaging calcium concentration dynamics in small neuronal compartments. Sci STKE 2004:p15. Medline

Yasuda R, Harvey CD, Zhong H, Sobczyk A, van Aelst L, Svoboda K (2006) Supersensitive Ras activation in dendrites and spines revealed by twophoton fluorescence lifetime imaging. Nat Neurosci 9:283-291. CrossRef Medline

Ye X, Carew TJ (2010) Small G protein signaling in neuronal plasticity and memory formation: the specific role of ras family proteins. Neuron 68 : 340-361. CrossRef Medline

Zhu JJ, Esteban JA, Hayashi Y, Malinow R (2000) Postnatal synaptic potentiation: delivery of GluR4-containing AMPA receptors by spontaneous activity. Nat Neurosci 3:1098-1106. CrossRef Medline

Zhu JJ, Qin Y, Zhao M, Van Aelst L, Malinow R (2002) Ras and Rap control AMPA receptor trafficking during synaptic plasticity. Cell 110:443-455. CrossRef Medline 